\title{
Rheological modification of recycled poly(ethylene terephthalate): Blending and reactive extrusion
}

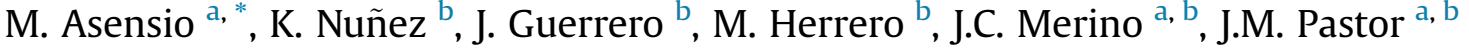 \\ a Department of Condensed Matter Physics, Escuela de Ingenierías Industriales, University of Valladolid, Paseo del Cauce, 59, 47011, Valladolid, Spain \\ ${ }^{\mathrm{b}}$ Foundation for Research and Development in Transport and Energy (CIDAUT), Parque Tecnológico de Boecillo, 47051, Valladolid, Spain
}

\section{A R T I C L E I N F O}

\section{Article history:}

Received 13 December 2019

Received in revised form

20 April 2020

Accepted 6 June 2020

Available online 19 June 2020

\section{Keywords:}

Poly(ethylene terephthalate)

Mechanical recycling

Rheology

PET blends

Reactive extrusion

\begin{abstract}
A B S T R A C T
The use of recycled PET (rPET) in long-term applications, such as composites, may provide an environmentally friendly solution for PET wastes. Main problem to overcome to use rPET in composites is its high viscosity which compromises the impregnation with the fibers during the consolidation process. As it is well known, PET undergoes thermo-mechanical and hydrolytic degradation during its mechanical recycling decreasing its viscosity and causing a loss of mechanical properties. For this reason, this paper takes into consideration a rheological modification during mechanical recycling to achieve the necessary fluidity for composites while maintaining the mechanical properties. Rheological modification was carried out by physical and chemical methods. Physical method was realized through blending with virgin PET (vPET) of low melt viscosity. Chemical method was performed on rPET, vPET and its blends by reactive extrusion. The effect of rheological modifications on the final thermal and mechanical properties was studied. Main results showed that both methods are able to decrease the viscosity without compromising mechanical properties. In addition, the chemical method during the reactive extrusion provided higher Elastic Modulus values.
\end{abstract}

() 2020 Elsevier Ltd. All rights reserved.

\section{Introduction}

Nowadays, there is a great concern to introduce the concepts of circular economy in the life cycle of plastic materials, especially in those that are used in applications of short useful life, such as packaging sector. Among plastics, poly(ethylene terephthalate) (PET) is one of the largest used in food and beverage packaging. PET, as a thermoplastic material, is recyclable. However, the short lifetime of most of its applications and its high consumption, that is over million tons per year, make the research in high-value applications of great interest [1,2]. Moreover, multilayer containers (barriers agents) or pigments additions (aesthetic purpose) in PET make difficult its recycling process technically and economically [3,4].

Currently, two main processes have been applied to recycle post-consumption PET (rPET): chemical and physical (thermomechanical recycling). Chemical recycling includes methanolysis, hydrolysis, glycolysis, aminolysis and ammonolysis. These processes provide a way to recover monomers, such as terephthalic acid and ethylene glycol in order to re-synthesize PET. Main

\footnotetext{
* Corresponding author.

E-mail address: marase@cidaut.es (M. Asensio).
}

disadvantages of chemical recycling are the high cost and polluting solvents used. On the contrary, mechanical recycling is a relatively simple process that has received considerable attention, since it is a route which save energy and avoid the emission of gases that contribute to global warming $[5,6]$. Mechanical recycling usually consists of eliminating impurities by sorting, grinding, washing and melting. The major drawback during mechanical recycling of PET is the degradation, which decreases the mechanical properties of the final recycled products compared with pristine raw materials $[7,8]$. Moreover, most of this waste cannot be recycled because it contains significant amounts of impurities such as inks and metals that interfere with the processing. This recycling technology is specially focused on transparent PET, due to material without pigments has greater value in applications such as the reuse in packaging market [9]. However, the cycle number is finite due to the continuous degeneration of the material [10]. This degradation results in a decrease of molecular weight and consequently a reduction of the materials performance. In this regard, to compensate the molecular weight reduction, numerous authors have studied the use of chain extenders additives. With these extenders is achieved an increase in the viscosity and molecular weight of PET to be used for blow molding applications [11-13]. 
To extend its area of applications, rPET are being reinforced to get a thermoplastic composite with improved properties [14,15]. Polymer composites are materials defined by the combination of a polymer matrix (thermoset or thermoplastic) and a reinforcing agent, mainly long fibers (carbon, glass or natural). To date, most composites are made by thermosetting matrices and they are being replaced by thermoplastics to improve the recyclability of these systems [16]. The capability to flow with heat makes thermoplastics materials recyclables and post-formable [17]. In addition, thermoplastic matrices in composites offers an increase of fracture toughness, higher impact tolerance, short processing cycle time and environmental stability. The main problem of thermoplastic materials for composites is their high viscosity which compromises the impregnation with the fibers or fabrics. It has been proved that thermoplastics with low viscosity improved the impregnation and the consolidation process [18].

To produce PET with low molecular weight and low viscosity several routes have been studied. The first route consists in the direct control during PET polymerization. PET with low viscosity can be obtained during synthesis by controlling the polymerization time, the monomers stoichiometry and by modifying the length of the chains. Moreover, it can be obtained adding multifunctional compounds to the polymerization to introduce branching [19]. Another route to obtain low viscosity polymers it can be by extrusion process. Melt blending with other polymers has received considerable interest during the last several decades due to the possibility of getting more desirable properties from thermal, rheological and mechanical behavior $[15,20]$. The use of virgin polymers in blends with recycled polymers of the same nature has been a common solution for the improvement of post-consumer materials [21]. On the other hand, it have been proved that the addition of hyperbranched polymers or multifunctional agents for branching during extrusion exhibit characteristics demonstrated such as low viscosity [22].

This work presents a highly innovative turn in research trends in the area of recycling of rPET in order to convert this problematic waste material in a raw material to the production processes of composites. To achieve this aim, it is necessary to control the viscosity decreasing the viscosity PET through the mechanical recycling method. Specifically, this research has been focused on the study of rheological modification by physical and chemical methods. For that purpose, the article is divided into three main goals: Firstly, as a zero-experimental, the influence of extrusion parameters on the viscosity of PET was analyzed. Secondly, rheological modification through physical method was carried out by melt blending. In this way, selected virgin PET with high fluidity was added to recycled PET to form blends. The influence of virgin PET on recycled PET was studied over the rheological properties. Finally, rheological modification was carried out through chemical method by reactive extrusion. The functionalization or chemical grafting of a monomer in the polymer structure during extrusion produced a "chain scission" followed by the grafting of a monomer of smaller size and greater chemical affinity. The major scientific and technological importance of this part of the research lies in studying the changes in the molecular structure of PET and blends modified by reactive extrusion, which have a great influence on the rheological, thermal and mechanical properties of these molten materials.

\section{Materials and methods}

\subsection{Raw materials}

Recycled PET (rPET) from a mixed of recycled bottles, was acquired from ClearPET in the form of flakes with an intrinsic viscosity of $0.8 \mathrm{dl} / \mathrm{g}$. Virgin poly(ethylene terephthalate) (vPET) with low viscosity, $0.63 \mathrm{dl} / \mathrm{g}$, was select to carry out rheological modification by physical method. vPET was purchased from NOVAPET (SPRIT L-21 BB1000).

The additive used for chemical modification (reactive extrusion) was 5-amino isophthalic acid $\left(\mathrm{C}_{8} \mathrm{H}_{7} \mathrm{NO}_{4}\right)$ from Sigma-Aldrich (Fig. 1). To avoid the hydrolytic degradation during processing, all PET samples were previously dried for $24 \mathrm{~h}$ at $110^{\circ} \mathrm{C}$ while $60^{\circ} \mathrm{C}$ for the additive in a vacuum oven.

The potential use of branched polymers as rheology modifiers was patented in 1992, especially used for coating applications [23]. It has been shown that the addition of polymers or multifunctional agents for polymer branching during extrusion results in a decrease in the viscosity of the material [24-26]. Therefore, high fluidity polyesters may be obtained by mixing polyesters in melt with monomers modifying the length of the chains using in particular diols, dicarboxylic acids, monoalcohol and/or monocarboxylic acids or else with water, diamines or monoamines [19]. Based on these statements the additive was selected due to its acid and amide terminal groups.

\subsection{Zero-experimental: PET processing parameters}

The main factors that may have an influence on PET viscosity during extrusion process (thermo-mechanical degradation) are screw speed, temperature and feed rate [27-29]. To obtain the most representative data, a Design of Experiments (DoE) was performed on the matrix of vPET because rPET material comes from different streams and its heterogeneity can interfere in the final results.

In order to find the optimal operation parameters for the PET extrusion a Taguchi DoE with three factors: screw speed, temperature and feed rate at two levels were done (see Table 1). Intrinsic viscosity was selected as response factor (output) measured. The treatment of the experimental data was carried out with the statistical software Minitab17. The complete table of experimental design with intrinsic viscosity values and interaction graphs are included in the supporting information (SI).

\subsection{Preparation of samples}

\subsubsection{Preparation of blends (physical method)}

Blends of rPET and vPET were prepared by melt blending in a corotating twin extruder Leistriz $27 \mathrm{GL}(\mathrm{L} / \mathrm{D}=36)$. The extrusion conditions were selected from the DoE carried out. Melt blending was carried out at a temperature of $265^{\circ} \mathrm{C}$, screw speed of $100 \mathrm{rpm}$ and feed rate of $5 \mathrm{~kg} / \mathrm{h}$.

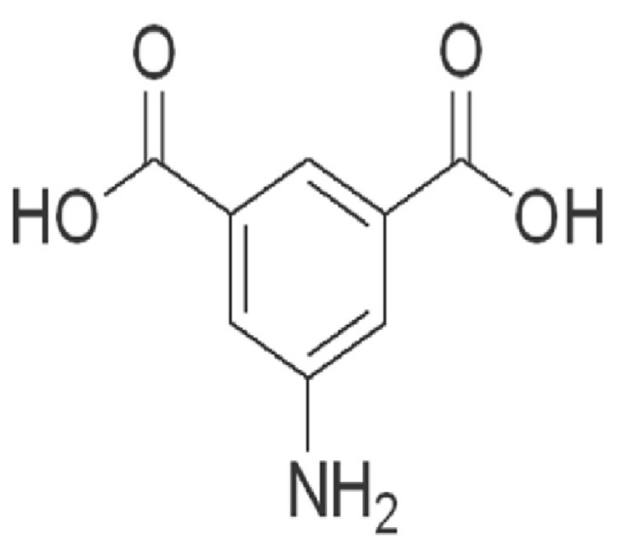

Fig. 1. Additive formula (5-amino isophthalic acid). 
Table 1

Factors and levels of DoE.

\begin{tabular}{lll}
\hline Factors & Levels & \\
\cline { 2 - 3 } & -1 & +1 \\
\hline Screw speed $(\mathrm{rpm})$ & 100 & 300 \\
Temperature $\left({ }^{\circ} \mathrm{C}\right)$ & 265 & 280 \\
Feed rate $(\mathrm{kg} / \mathrm{h})$ & 5 & 9 \\
\hline
\end{tabular}

Table 2

Variation of additive concentration.

\begin{tabular}{ll}
\hline Sample & Additive (wt \%) \\
\hline vPET & - \\
vPET $0.25 \%$ & 0.25 \\
vPET $0.5 \%$ & 0.5 \\
vPET $1 \%$ & 1 \\
\hline
\end{tabular}

\subsubsection{Reactive extrusion (chemical method)}

Firstly, variations of additive concentration were studied over vPET. The use of rPET in this concentration study was discarded to avoid heterogeneous results that could come from different sampling of a recycled material. The reactive extrusion of vPET with different amounts of 5-aminoisophthalic acid was performed with the concentration variations of $0.25-1 \mathrm{wt} \%$ (Table 2).

Subsequently, both physical and chemical methods were carried out synergistically. Selected extrusion conditions from DOE $\left(265^{\circ} \mathrm{C}\right.$, $100 \mathrm{rpm}, 5 \mathrm{~kg} / \mathrm{h}$ ) were used in both methods. Compositions of physically and chemically modified blends are showed in Table 3. To carry out chemical method $0.25 \%$ concentration was select from the previous study of additive concentration.

\subsection{Injection molding}

The pelletized samples from extrusion were injected using a Krauss Maffei KM 200 injection molding machine. The temperature profile of the cylinders was 240 to $270^{\circ} \mathrm{C}$ and the mold temperature was $50{ }^{\circ} \mathrm{C}$. The injected specimens were type $1 \mathrm{~A}$ (according to ISO 527-1), which were used for the mechanical characterization (Elastic Modulus and Tensile Strength).

\subsection{Characterization}

\subsubsection{Rheological measurements}

2.5.1.1. Intrinsic viscosity. The intrinsic viscosity $(\mu)$ was determinated under ASTM-D4603-03 at $30^{\circ} \mathrm{C}$ in an Ubbelholde viscometer using the mixture 50/50 (wt/wt) phenol/1,1,2,2-tetrachloroethane as solvent. Three independent replicates for each sample were prepared.
2.5.1.2. Dynamic rheometry. HAAKE Rheostress 600 dynamic rheomether was utilized to measure the viscosity in molten state. Plateplate geometry $(20 \mathrm{~mm})$ and a selecting gap between plates of $1.6 \mathrm{~mm}$ were used. The complex viscosity $\left(\mu^{*}\right)$ was measured as a function of temperature from $265^{\circ} \mathrm{C}$ to $300^{\circ} \mathrm{C}$ and frequency was set at $1 \mathrm{~Hz}$. In order to avoid possible molar mass changes during sample preparation, pellets were deposited directly into the pre-heated rheometer. Three independent replicates for each sample were tested.

\subsubsection{Thermal analysis}

2.5.2.1. Differential scanning calorimetry (DSC). Melting $\left(\mathrm{T}_{\mathrm{m}}\right)$, glass transition $\left(T_{g}\right)$ and crystallization temperatures $\left(T_{c}\right)$, as well as crystallinity $\left(\mathrm{X}_{\mathrm{c}}\right)$ of all samples were measured by Differential Scanning Calorimetry (DSC), with Mettler Toledo DSC 851e. The range of temperatures was from 25 to $300{ }^{\circ} \mathrm{C}$ and at a heating rate of $20{ }^{\circ} \mathrm{C} / \mathrm{min}$ under nitrogen flow. Materials were heating above their melting point in order to removed thermal history. Furthermore, crystallinity degree $(X c)$ was calculated according to the next equation with a select enthalpy for fully crystalline PET of $\Delta H_{0}=$ $140 \mathrm{~J} / \mathrm{g}$ [30]. The additive content is not considered for the calculation of crystallinity since the final quantity used is $0.25 \%$ and does not imply significant changes in the final calculation. Two sample of each material were tested.

$X \mathrm{c}(\%)=\frac{\Delta H_{m}-\Delta H_{c c}}{\Delta H_{0}} \times 100$

\subsubsection{Structural analysis}

2.5.3.1. Gel permeation column GPC. The determination of molecular weights was carried out using a high resolution liquid chromatography with a photodiode detector (HPLC-PDA) using a gel permeation column (GPC) Waters 1515 with Waters 717 plus autosampler. For calibration, polymethyl methacrylate (PMMA) standards of known molecular weights have been used. The calculation of the molecular weight distribution of the samples is carried out using the Empower software from Waters 996 PDA.

Columns were Phenomenex, Phenogel $5 \mu \mathrm{m}$ Linear, $7.8 \times 300 \mathrm{~mm}$. Elution solvent: Hexafluoroisopropanol (HFIP) + $10 \mathrm{mM}$ sodium trifluoroacetate $(1 \mathrm{~mL} / \mathrm{min})$; detector wavelength: $230 \mathrm{~nm}$; Column temperature $25{ }^{\circ} \mathrm{C}$; Samples were dissolved in elution solvent at $2 \%$ concentration and passed through a $0.22 \mu \mathrm{m}$ PFTE microfilter to remove any solid residue. Two replicates were prepared from each sample.

2.5.3.2. Fourier-transform infrared spectroscopy FTIR. A Bruker spectrometer model Vertex 70 and a total attenuated reflectance accessory (ATR) were used in order to determine how the presence of the additive affect the structure of PET during the reactive extrusion. An analysis of the IR spectra of pure vPET and the vPET

Table 3

Samples prepared by physical and chemical methods.

\begin{tabular}{lll}
\hline Method & Sample & rPET: vPET (wt: wt\%) \\
\hline Physically modified blends & rPET & $100: 0$ \\
& $75: 25$ & $75: 25$ \\
& $50: 50$ & $50: 50$ \\
& $25: 75$ & $25: 75$ \\
Chemicallymodified blends & vPET & $0: 100$ \\
& rPET_0.25\% & $100: 0$ \\
& $75: 25 \_025 \%$ & $75: 25$ \\
& $50: 50 \_0.25 \%$ & $50: 50$ \\
& $25: 75 \_0.25 \%$ & $25: 75$ \\
\end{tabular}


Main Effects Plot for Intrinsic viscosity (dl/g)

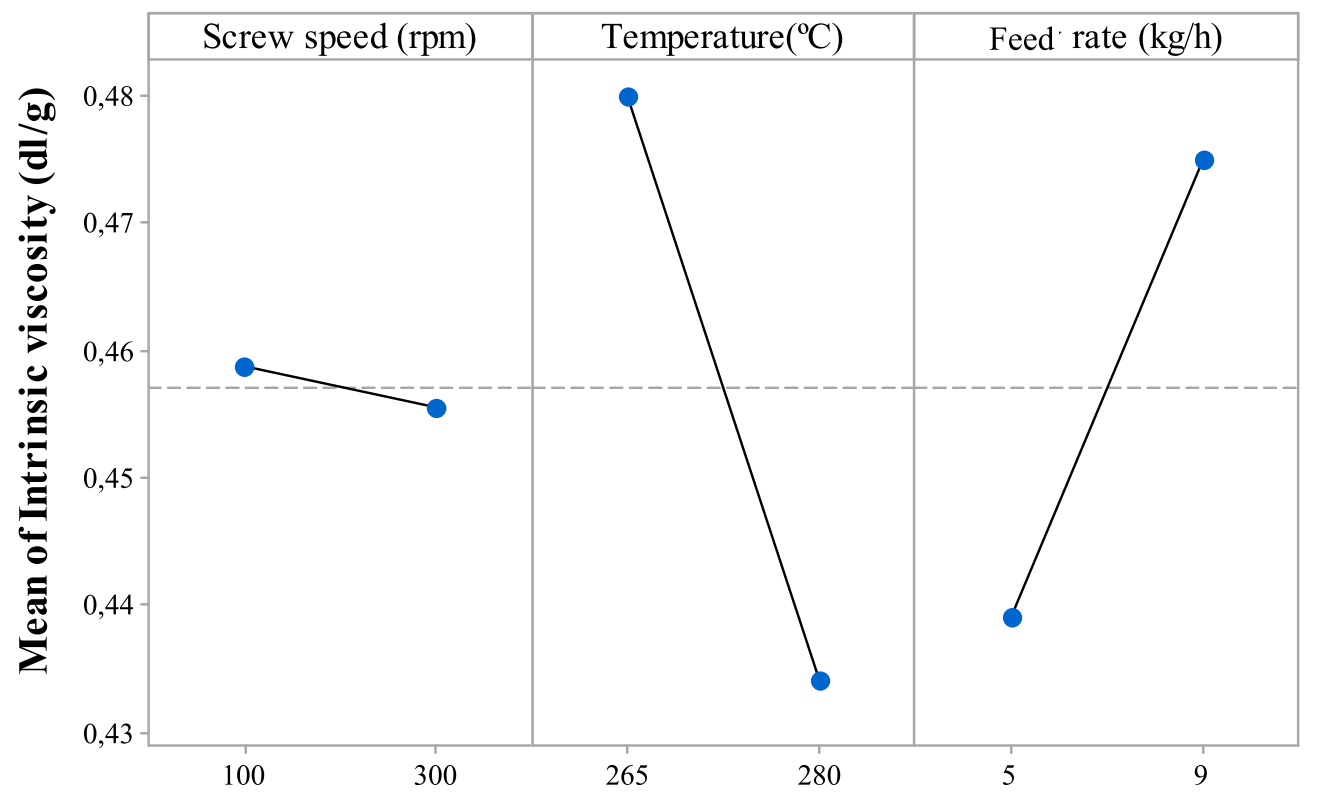

Fig. 2. Graph of main effects for the extrusion factors studied.

chemically modified by reactive extrusion with a high amount of additive (vPET 20\%) was carried out. In order to evaluate the changes resulting from the presence of the additive, the spectra have been normalized to the IR band corresponding to the vibration of $\mathrm{CH}_{2}$ at $1340 \mathrm{~cm}^{-1}$. This wavelength has been conscientiously selected after analyzing the vibration peaks of the functional groups of both species. Other authors usually use $1400 \mathrm{~cm}^{-1}$ as the normalization band, because it corresponding to the vibration modes of the benzene ring that remains constant in their studies of PET degradation [31,32]. However, in this case, the IR spectra of PET and the isolated additive have similar vibration modes at this frequency due to the functional groups they have in common: benzene rings and carboxylic groups. Three different samples were analyzed by FTIR resulting in repeatable values between them.

\subsubsection{Mechanical analysis}

2.5.4.1. Tensile test. The Elastic Modulus and Tensile Strength were measured at room temperature with an Instron model 5500R60025

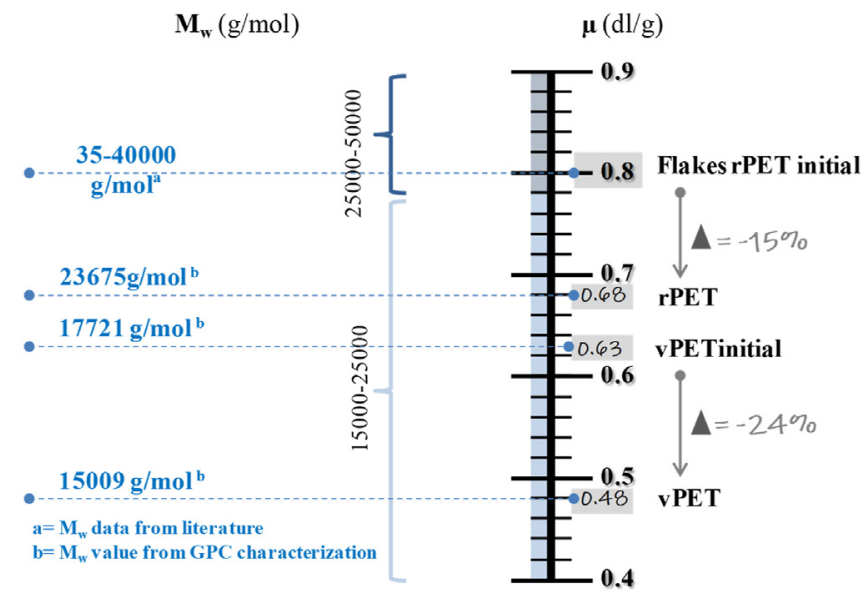

Fig. 3. Diagram of viscosity and molecular weight ranges used. at a speed of $1 \mathrm{~mm} \mathrm{~min}^{-1}$ and $10 \mathrm{~mm} \mathrm{~min}^{-1}$ respectively, according to ISO 527-1. For each sample five specimens were tested and values of the mechanical parameters were calculated.

\subsubsection{Morphological analysis}

Scanning electron microscopy (SEM) analysis was performed using a FESEM Hitachi H-7000 in order to study the blends morphology. The samples were cryogenically-fractured from the injection molded specimens and coated with gold-palladium alloy ( $\mathrm{Au}-\mathrm{Pd})$.

\section{Results and discussion}

\subsection{Zero-experimental: influence of extrusion parameters}

Standard statistical conditions used in experimental designs were set (95\% of confidence). Fig. 2 shows the graph of main effects for the extrusion process over $\mu$. In each graph, the influence of each factor on the response $(\mu)$ is quantified by the slope of the line joining the two proposed levels. The interactions between factors have been analyzed both in the interaction diagram and in the Pareto diagram (graphics in SI).

As a result of this experiment, it is noted that temperature and feed rate were the factors more involved in the decrease of $\mu$ in contrast to the screw speed.

High temperature processed sample $\left(280^{\circ} \mathrm{C}\right)$ showed the lowest $\mu$ values. This result can be explained by thermal degradation which PET undergoes during extrusion process [29,33]. Furthermore, it was shown that feed rates on its low level $(5 \mathrm{~kg} / \mathrm{h})$ reached lower values of $\mu$. This can be explained due to at low feed rates, the residence time of PET in the extruder is longer, and consequently, PET undergoes longer thermal degradation. This condition would have a similar impact in $\mu$ as working with higher temperatures.

From these studies, the following extrusion conditions were selected: $100 \mathrm{rpm}, 265{ }^{\circ} \mathrm{C}, 5 \mathrm{~kg} / \mathrm{h}$. The screw speed of $100 \mathrm{rpm}$ was selected for operational reasons. Temperature of $265^{\circ} \mathrm{C}$ was select to avoid further thermal degradation at $280{ }^{\circ} \mathrm{C}$. As above mentioned, lower feed rates allowed obtaining low values of $\mu$, without subjecting PET to high temperatures. 


\section{Chain scission reactions}

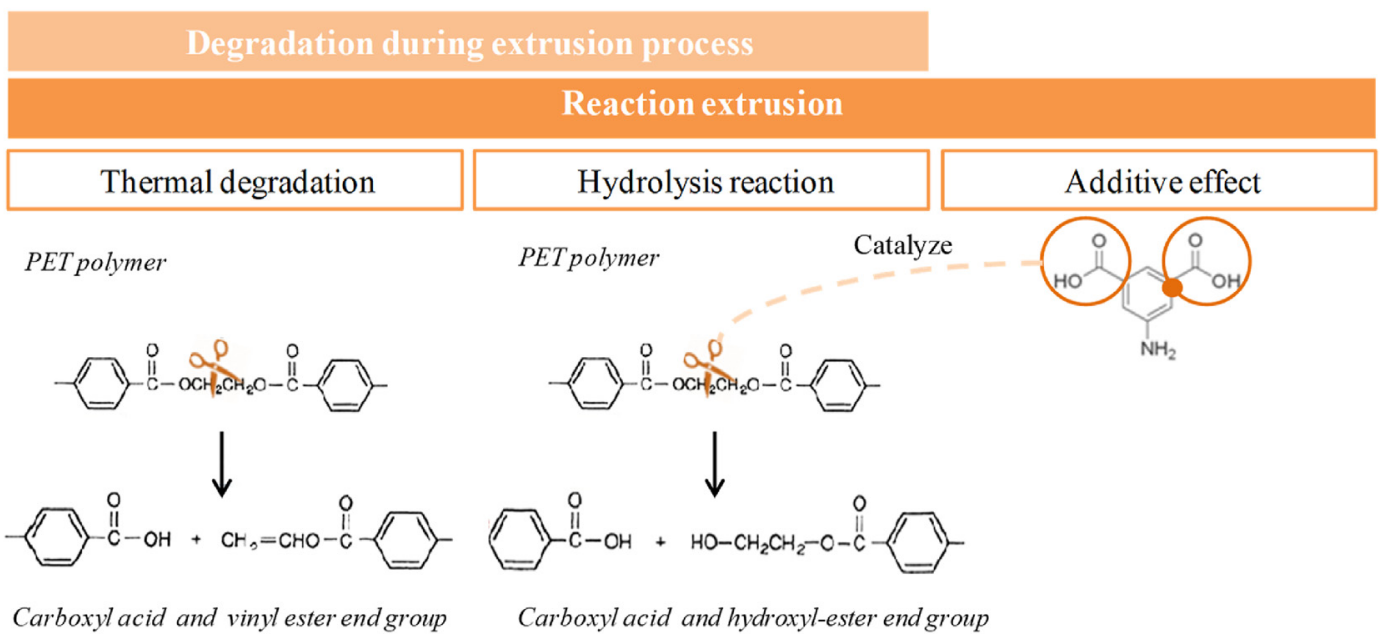

Fig. 4. Effect of processing on the chain scission reactions of PET ester linkages.

Once the conditions have been selected, both materials, vPET and rPET, were extruded at selected conditions. Fig. 3 shows a diagram for a better understanding of the viscosity values and molecular weight at which it has been worked. $\mu$ of vPET decrease from
$0.63 \mathrm{dl} / \mathrm{g}$ to $0.48 \mathrm{dl} / \mathrm{g}$ and for $\mathrm{rPET}$ decrease from $0.80 \mathrm{dl} / \mathrm{g}$ to $0.68 \mathrm{dl} /$ g. Extruded vPET has undergone a decrease of $24 \%$ in viscosity comparing with initial vPET. Extruded rPET has decreased a $15 \%$ in viscosity respect the initial rPET. This result shows that both
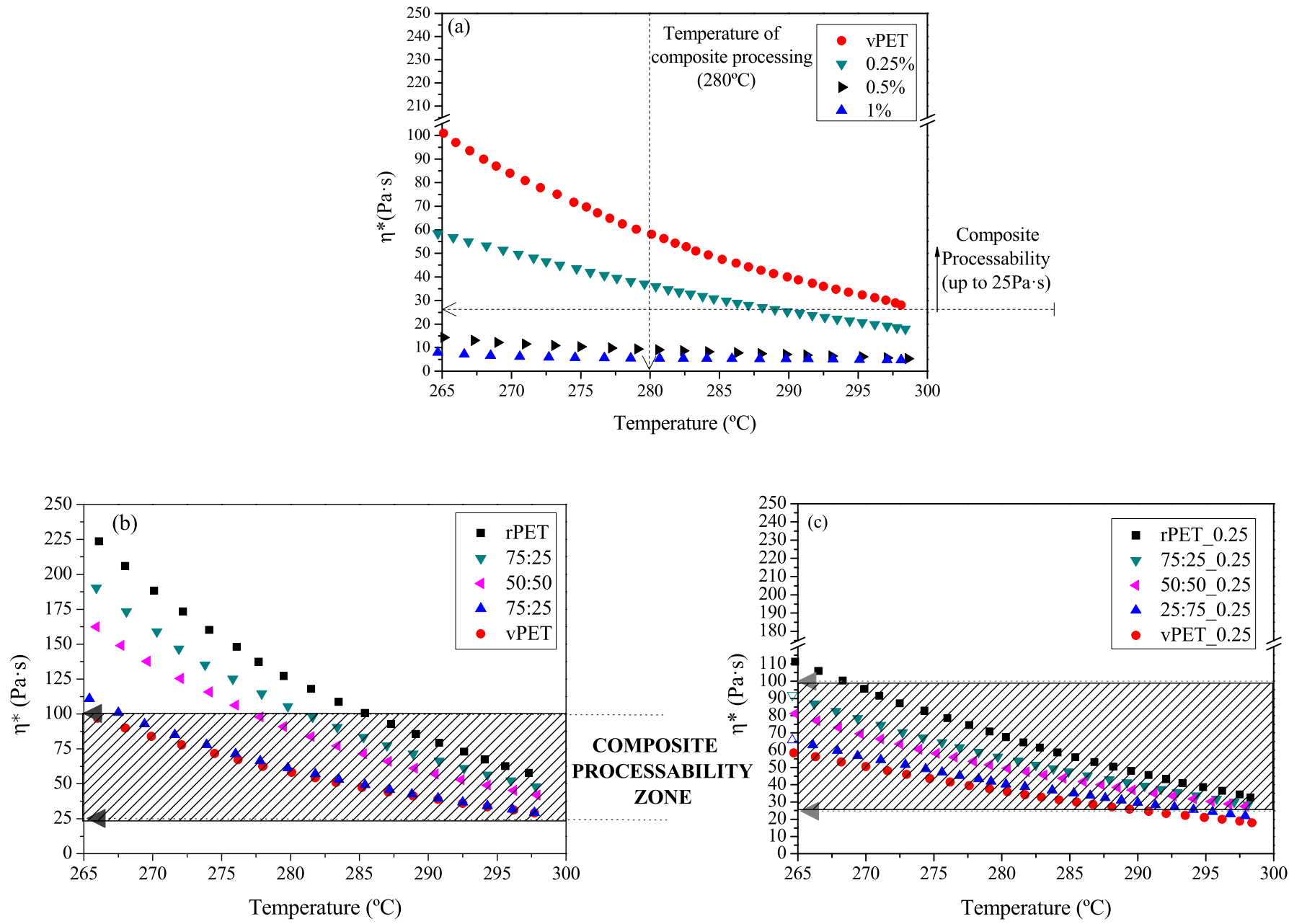

Fig. 5. Temperature sweeping of variations of additive concentration on vPET (a), physically (b) and chemically (c) modified blends. 


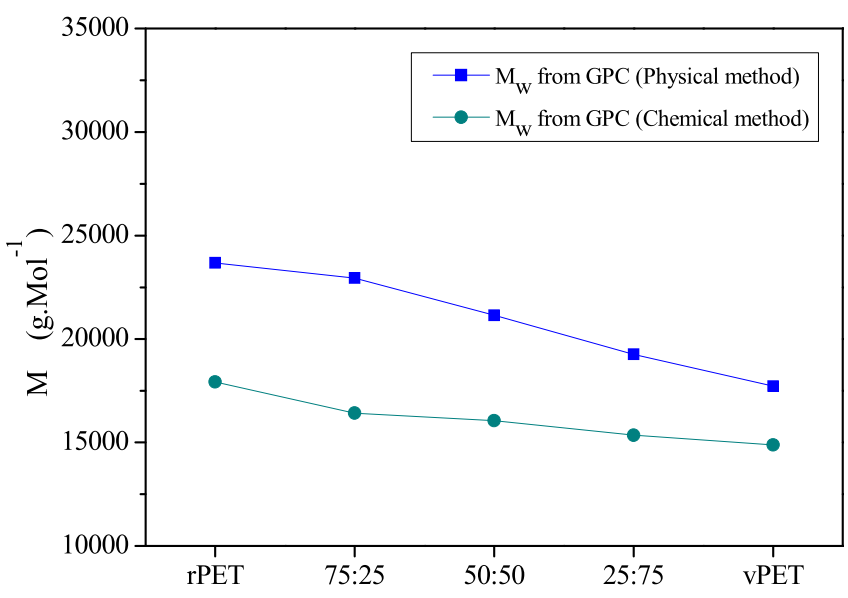

Fig. 6. Molecular weight of samples physically ( $\square$ ) and chemically (o) modified blends.

materials had similar response to the process of extrusion. However, vPET presented higher change in viscosity being more sensitive to degradation. This may be because vPET present chains with lower molecular weight than rPET (see Fig. 3). Although rPET has higher molecular weight values, the molecular weight distribution is broader due to the heterogeneity of the origin samples.

Once select the extrusion conditions (zero experimental) and studied its influence on the $\mu$, two methods were used for the rheological modification (Physical and Chemical). Firstly, physical method was carried out by blending recycled PET with the select virgin PET with high fluidity. Secondly, the chemical method by reactive extrusion was developed in vPET, rPET and its blends.

In Fig. 4 it is shown a representative scheme of the scission reactions that PET undergoes during extrusion corresponding to thermal degradation and hydrolytic degradation reactions [3].

On the left side of Fig. 4 it is shown thermal decomposition of an ester linkage that gives carboxyl acid end groups and vinyl ester end groups. Next, the Figure show the hydrolysis reaction of PET that gives carboxyl acid end groups and hydroxyl-ester end groups. The hydroxyl and carboxyl end groups in rPET plays a vital role in decreasing the molecular weights during processing. It was reported that during rPET melt processing, a decrease in molecular weight and an increase of carboxyl content is observed [3].

The additive (5-amino isophtalic acid) can carry out two types of reactions during the chemical modification. Acids groups

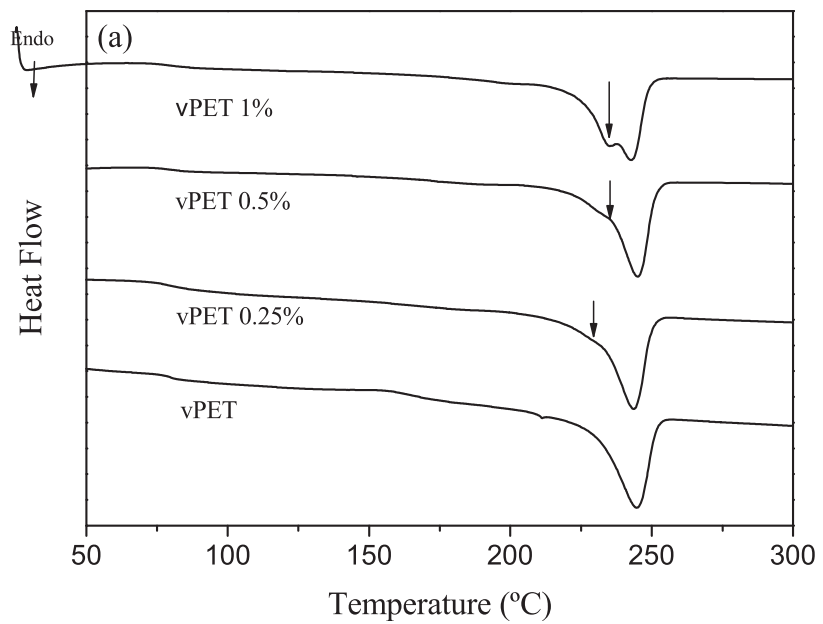

Table 4

Thermal data extracted from DSC curves.

\begin{tabular}{lllll}
\hline Sample & $\mathrm{T}_{\mathrm{g} \pm 0.5{ }^{\circ} \mathrm{C}}$ & $\mathrm{T}_{\mathrm{m} \pm 0.5{ }^{\circ} \mathrm{C}}$ & $\mathrm{T}_{\mathrm{c} \pm 0.5{ }^{\circ} \mathrm{C}}$ & $\mathrm{X}_{\mathrm{c} \pm 1 \%}$ \\
\hline vPET & 80.1 & 244.6 & 166.7 & 27 \\
vPET $0.25 \%$ & 79.6 & 243.6 & 181.6 & 27 \\
vPET $0.5 \%$ & 79.6 & 245.0 & 189.1 & 28 \\
vPET $1 \%$ & 79.5 & 242.7 & 198.7 & 29 \\
\hline
\end{tabular}

present in the additive can catalyze the hydrolysis reaction acting as scission breakage and, at the same time, act as a functional graft. This can occur by the formation of anhydride groups between the carboxyl groups of the additive and the resulting from the degradation [34].

Changes in viscosity by physical method involve degradation during extrusion process (thermal and hydrolytic) and the effect of the blend. Chemical method involves all phenomena, physical (blends and extrusion) and chemical (reactive extrusion).

\subsection{Material performance characterization}

\subsubsection{Rheological behavior (physical and chemical method)}

Rheological properties have been a useful tool for quantifying the effect of physical modification by blending and chemical modification by reactive extrusion from a change in complex viscosity. Complex viscosity $\left(\eta^{*}\right)$ for variations of additive concentration on vPET ((Fig. 5(a)) and physically and chemically modified blends (Fig. 5(b and c)) is plotted against temperature. The figures show a band indicating the values between 25 Pa.s and 100 Pa.s as a threshold for the correct processability of PET to develop thermoplastic composites.

An additive percentage of $0.25-1 \%$ was used to select the appropriated concentration for the chemical modification. From the results of this study (Fig. 5(a)), concentration of $0.25 \%$ additive was selected to carry out the chemical method. This is because complex viscosity values below $25 \mathrm{~Pa} \cdot \mathrm{S}$ (such as concentrations of 0.5 and 1\%) hinders the processability of composite process due to the high fluidity.

As mentioned above, vPET has lower viscosity (and lower molecular weight) than rPET (Fig. 5 (b)). For this reason, as can be seen in the graph, the viscosity decreases when the amount of vPET is increased causing a lubricant effect in the polymeric blend reducing the viscosity of the mixture. This is indicated by the molecular weight decrease as blend ratio of vPET was increased [35]. This fact can be seen in the GPC results.

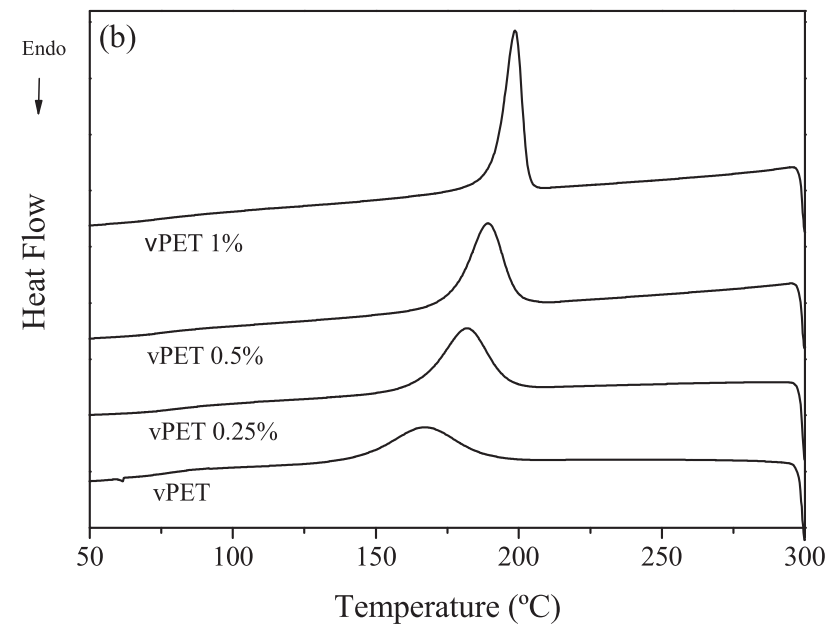

Fig. 7. Melting (a) and crystallization (b) of vPET with different additive percentages. 


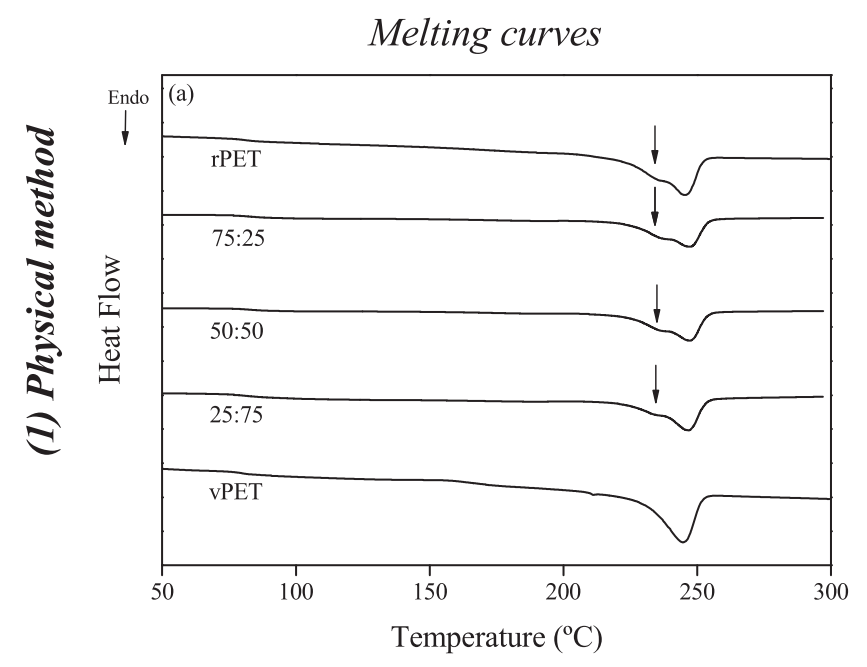

Crystallization Curves
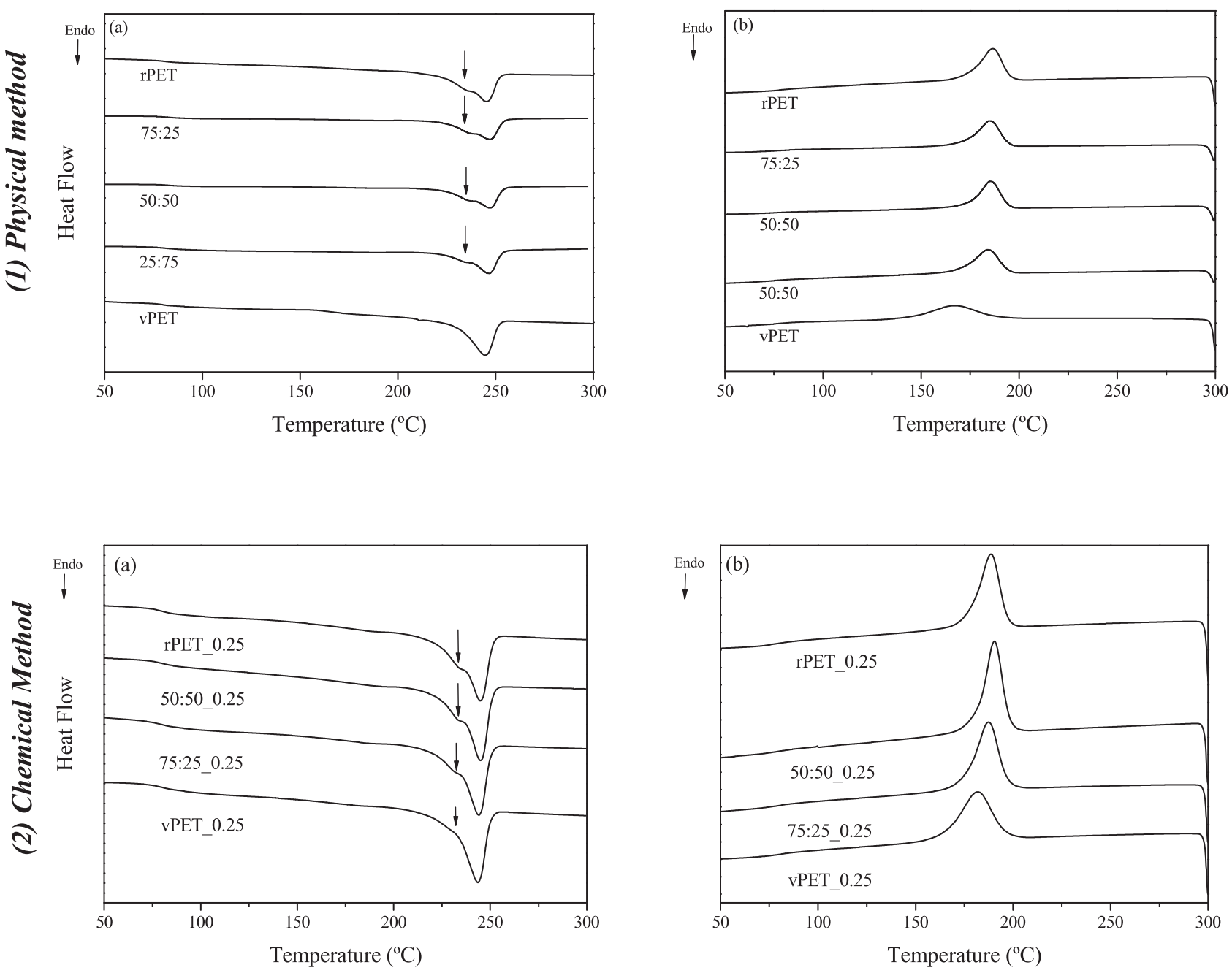

Fig. 8. Curves of melting (a) and crystallization (b) of physically (1) and chemically (2) modified blends.

Table 5

Thermal data of pure compounds and blends.

\begin{tabular}{|c|c|c|c|c|c|}
\hline Sample & rPET:vPET & $\mathrm{T}_{\mathrm{g} \pm 0.5^{\circ} \mathrm{C}}$ & 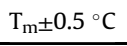 & $\mathrm{T}_{\mathrm{c} \pm 0.5^{\circ} \mathrm{C}}$ & $\mathrm{X}_{\mathrm{c} \pm 1 \%}$ \\
\hline \multirow[t]{5}{*}{ Physically modified blends } & $100: 0$ & 81.1 & 245.3 & 186.5 & 27 \\
\hline & $75: 25$ & 82.0 & 247.5 & 184.8 & 22 \\
\hline & $50: 50$ & 82.8 & 247.4 & 185.1 & 23 \\
\hline & $25: 75$ & 81.7 & 246.8 & 183.7 & 24 \\
\hline & $0: 100$ & 80.1 & 244.6 & 166.7 & 27 \\
\hline \multirow[t]{5}{*}{ Chemically modified blends } & rPET_0.25 & 80.3 & 244.9 & 188.2 & 26 \\
\hline & 75:25_0.25 & 79.9 & 244.9 & 190.5 & 27 \\
\hline & 50:50_0.25 & 79.8 & 244.9 & 190.4 & 28 \\
\hline & 25:75_0.25 & 80.7 & 244.1 & 187.4 & 28 \\
\hline & vPET_0.25 & 79.6 & 243.6 & 181.6 & 27 \\
\hline
\end{tabular}

In this case, according to the physical method, up to $50 \%$ of the recycled PET could be used as matrices in composites (which are the samples showed in Fig. 5(b) in the processability band).

All chemically modified samples (Fig. 5(c)) showed lower viscosity values in comparison to the physically modified PET samples (Fig. 5(b)). This decrease in complex viscosity is associated with the macromolecular chains scissions caused by the additive, making samples flow more easily and therefore achieve low viscosity values. This method would allow using a higher recycling content (even
$100 \%$ ) of rPET as matrix for composites. In addition, all materials are within the composite processability zone, even at low temperatures.

\subsubsection{Molecular weight determination}

Fig. 6 show the Molecular weight $\left(\mathrm{M}_{\mathrm{w}}\right)$ of physically and chemically modified samples was obtained by GPC.

In Fig. 6, rPET showed higher molecular weight than vPET. These results are in accordance with the rheological properties, where rPET showed the highest viscosity values. It is well known, that 

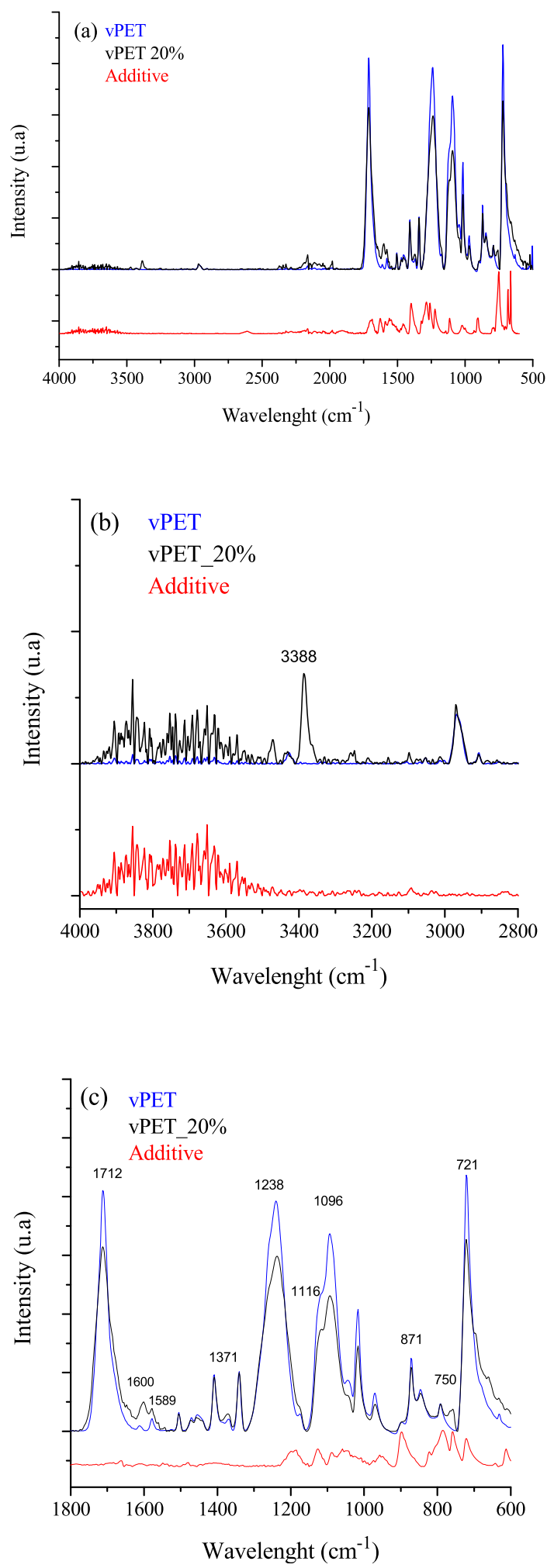

Fig. 9. FTIR spectra of: (a) vPET, vPET_20\% additive and isolated additive (4000$500 \mathrm{~cm}^{-1}$ ) (b) FTIR spectra in the $4000-2800 \mathrm{~cm}^{-1}$ and (c) $1800-600 \mathrm{~cm}^{-1}$ range.

rheological properties of polymers depend strongly on their molecular structure, especially on their molecular weight $\left(\mathrm{M}_{\mathrm{w}}\right)$. Furthermore, the molecular weight decreased when vPET (blending) and the additive (reactive extrusion) was incorporated to rPET and blends.

\subsubsection{Thermal properties}

Thermal properties of samples obtained by physical and chemical methods were studied through DSC. Moreover, vPET with different amount of additive $(0.25 \%-1 \%)$ were thermally studied. This study allowed the selection of the $0.25 \%$ additive to be evaluated through chemical method.

3.2.3.1. Effect of additive concentration. Melting (a) and crystallization (b) curves of vPET modified with different percentages of additive are showed in Fig. 7. Thermal data calculated from these curves are displayed in Table 4.

In the melting curves (Fig. 7 (a)) a second peak at a lower temperature is observed when the amount of additive is increased. The presence of these multiple peaks indicates variations in the distribution of crystalline sizes. Melting at lower temperatures indicates the formation of smaller crystals arising from chain scission. The additive promoted the scissions of the polymeric chains forming two crystalline sections differentiated in the same endothermic peak. This behavior is similar to the chains scission suffered by PET when it is subjected to several extrusion cycles [28]. Second peak of the melting endothermic does not show a trend when the amount of additive increase (variation of $\pm 2{ }^{\circ} \mathrm{C}$ ), maintaining the majority crystallinity section. Moreover, as can be seen in Table $4, \mathrm{~T}_{\mathrm{g}}$ values do not show significant changes with the increase of additive concentration. This maintenance of $\mathrm{T}_{\mathrm{g}}$ temperature is important for composite manufacturing processes.

In the crystallization curves (Fig. 7(b)) it can be observed how narrower peaks at higher crystallization temperature appeared when the additive concentration is increased. Shift to higher crystallization temperatures and narrower peaks indicates that crystallization process occurs earlier than pure vPET (greater ability to crystallize) [27]. This fact could be explained by the chain scissions caused by the additive which improves chain packing and, consequently, shifting $\mathrm{T}_{\mathrm{c}}$ to higher temperatures. Crystallinity degree did not present significative changes (variation of $\pm 2{ }^{\circ} \mathrm{C}$ ).

3.2.3.2. Physical and chemical method. Fig. 8 shows the melting (a) and crystallization (b) curves of blends from physical (1) and chemical (2) methods. The $\mathrm{T}_{g}, \mathrm{~T}_{\mathrm{m}}$ and $\mathrm{T}_{\mathrm{c}}$ temperatures as well as $\mathrm{X}_{\mathrm{c}}$ calculated from DSC curves are displayed in Table 5.

In the physical method (Fig. 8(1a)), it is observed that the melting peak presents a shoulder at lower temperature for blends with high rPET ratio (typical of thermo-mechanical degradation of the rPET). Multiple melting peaks of rPET have already been observed in PET during DSC thermal analysis by other authors $[3,36]$. They suggested that multiple melting peaks are attributed to the distribution of crystals with different lamellar thickness and to the melting of different crystal structures. No significative differences can be observed in $\mathrm{T}_{\mathrm{g}}$ and $\mathrm{T}_{\mathrm{m}}$ values (Table 5 ).

Crystallization curves show a decrease in the crystallinity values in blends. This may be due smaller crystals formed with the addition of vPET.

Moreover, Table 5 shows that $\mathrm{T}_{\mathrm{c}}$ of $\mathrm{vPET}$ is lower than $\mathrm{rPET}$. This fact is related to the thermal cycles suffered by rPET when it is recycled (it tend to higher $\mathrm{T}_{\mathrm{c}}$ values) which means that rPET crystallization begins at higher temperature [35]. Therefore, when the ratio of vPET is increased in blends the crystallization temperature decreases.

In the chemical method, it can be observed in Fig. 8(2a) a second melting peak of the melting endothermic, which also appeared in the melting curves of physical method. This second peak is higher due to the effect of the additive and the vPET in blends acting synergistically. As can be observed in Table $5, \mathrm{~T}_{\mathrm{g}}$ and $\mathrm{T}_{\mathrm{m}}$ values did not show significant changes. The additive causes a stabilizing effect of the glass transition temperature and the melting 

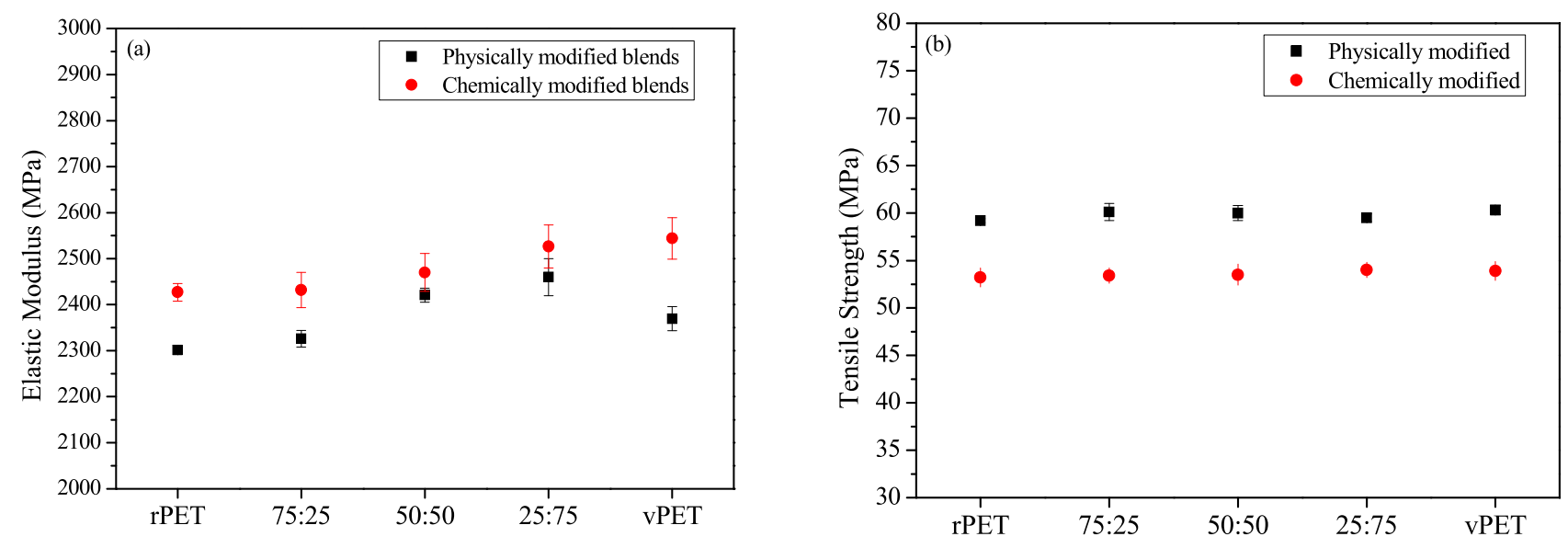

Fig. 10. Elastic Modulus (a) and Tensile Strength (b) comparison for physically ( $\square$ ) and chemically (๑) modified blends.

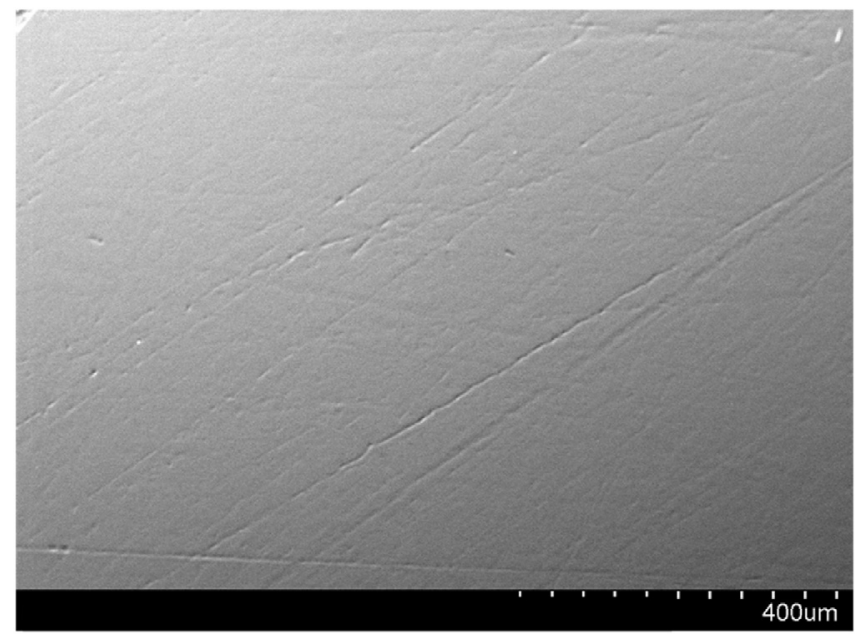

Fig. 11. SEM micrograph of the injected specimen corresponding to the mixture 50:50 (rPET:vPET).

temperature. Crystallization curves show that $\mathrm{T}_{\mathrm{C}}$ is higher in the blends (Fig. 8(2b)). There are no significant changes in the crystallinity with increasing percentage of vPET in modified blends. This fact may be associated with aggregation of crystals in a more orderly way when incorporating the additive.

\subsubsection{Fourier-transform infrared spectroscopy (FTIR)}

Fig. 9 (a) shows the spectra of vPET, vPET_20\% and the isolated additive (4000-500 $\mathrm{cm}^{-1}$ ). Fig. 9 (b) shows an enlargement of the wavelength area of $4000-2800 \mathrm{~cm}^{-1}$ and Fig. 9 (c) $1800-600 \mathrm{~cm}^{-1}$.

These spectra showed a decrease in intensity and a widening of the bands corresponding to vibration modes of the aromatic ring (721, $\left.871,1238 \mathrm{~cm}^{-1}\right)$, carboxylic $\left(1712 \mathrm{~cm}^{-1}\right)$ and carboxylic acid groups $\left(1096 \mathrm{~cm}^{-1}\right)$ with the incorporation of the additive. The widening of the bands and the loss of intensity is due to a doubling of the vibration modes that cause of part of the molecules vibrate at close but different wavelengths. On the other hand, bands of the $\mathrm{C}-\mathrm{C}$ bonds of the ring $\left(1589 \mathrm{~cm}^{-1}\right)$ show an increase in intensity as a result of the increase of aromatic rings with the incorporation of the additive.

According to the scheme of chain scission reactions suffered by PET (Fig. 4), $\mathrm{O}-\mathrm{CH}_{2}$ bonds are susceptible by the action of the additive generating $-\mathrm{OH}$ terminal groups. The evidence of the breakage of this link can be seen in the decrease of the intensity of the corresponding vibration band $\mathrm{O}-\mathrm{CH} 2$ at $1116 \mathrm{~cm}-1-\mathrm{OH}$ groups resulting from vPET fragmentation due to the additive are generally linked $-\mathrm{OH}$ groups with a large band between 3100 and $3500 \mathrm{~cm}^{-1}$. Free $-\mathrm{OH}$ groups are given in evidence by a narrow peak between 3500 and $3700 \mathrm{~cm}^{-1}$.

Regarding the additive, its vibrational bands are at similar wavelengths to PET bands as it has common functional groups. That is the reason because bands present a widening caused by the doubling (721 and $1240 \mathrm{~cm}^{-1}$ ). One of the characteristic bands of the additive, which is not present in PET, is the amine group which is evidenced by a vibration mode at $3388 \mathrm{~cm}^{-1}$ and $750 \mathrm{~cm}^{-1}(-\mathrm{NH}$ bonds in primary amines such as those of the additive).

Moreover, the alkenes present in the vinyl ester end group formed by the thermal degradation of PET are evidenced due to their characteristic bands $C=C$ stretch in $1600 \mathrm{~cm}^{-1}$. It is reported that the presence of these vinyl ester groups have no influence on the viscosity of the material [34].

Anhydride groups present the same $\mathrm{C}=\mathrm{O}$ vibrational modes than PET but at much higher wavelengths: $\mathrm{C}=\mathrm{O}$ functions from esters (PET) are located at $1712 \mathrm{~cm}^{-1}$ [37]. $\mathrm{C}=\mathrm{O}$ functions of anhydrides are located at $1870-1810 \mathrm{~cm}^{-1}$ and $1810-1760 \mathrm{~cm}^{-1}$. The Figure does not show bands over $1800 \mathrm{~cm}^{-1}$ so the anhydride group cannot be evaluated.

\subsubsection{Mechanical properties}

Fig. 10 shows a comparative graph of mechanical properties between physical method (blending) and chemical method (blending and reactive extrusion).

From this comparative, some conclusions are evidenced. Firstly, vPET show a slightly higher Elastic Modulus values than rPET. This means that vPET addition in blends (through both methods) produces an increase in these values.

In the case of the physical method it can be seen how the mixtures present higher modulus values than the pure compounds. This can be associated to the results observed in the thermal properties, where the mixtures present less crystallinity than the pure compounds. In crystalline polymers the elastic deformation is low since the chains are almost straight and parallel to each other.

On the other hand, comparing with physical method, the incorporation of the additive in PET matrices and blends through chemical method caused an increase in Elastic Modulus. This fact may be due to the insertion of aromatic groups which constitute the molecular structure of the additive.

Fig. 10 (b) shows that pure samples (vPET and rPET) and blends have similar Tensile Strength values (59-60 MPa). Samples modified through chemical method showed lower values of Tensile Strength 
than physically modified samples (around 53-54 MPa). This fact may be related with thermal properties results, where the larger crystals formed through physical method withstand more load than crystals formed by the chemical method (shorter crystals).

\subsubsection{Morphological analysis}

The injected sample of the 50:50 mixture (rPET:vPET) was analyzed by SEM. Fig. 11 shows the micrograph of the sample where a homogeneous mixture is observed. Therefore, there is no evidence of two-phase formation between rPET and vPET.

\section{Conclusion}

In this work two methods have been studied in order to decrease the viscosity of rPET material to an optimal level while maintaining the mechanical properties. From this work, the following conclusions are presented:

- Physical rheological modification by blending has allowed decrease the viscosity values of rPET with the incorporation of vPET. Moreover, this incorporation resulted in an increase of mechanical properties such as Elastic Modulus. Tensile Strength did not undergo significant changes with the incorporation of vPET.

- Chemical rheological modification by reactive extrusion has allowed obtaining lower viscosity values than physical method. In addition, the insertion of the additive provided an improvement of the Elastic Modulus. These results provide an rPET with an improved combination of flowability and Elastic Modulus.

It is therefore, both methods would enable melt processing rPET with low viscosity at lower pressures and/or temperatures for performance composite application. However, chemical method would allow used $100 \%$ rPET and physical method only a maximum of $50 \%$ of rPET as matrices for composites.

\section{Declaration of competing interest}

The authors declare that they have no known competing financial interests or personal relationships that could have appeared to influence the work reported in this paper.

\section{CRediT authorship contribution statement}

M. Asensio: Investigation, Resources, Writing - original draft. K. Nuñez: Conceptualization, Funding acquisition, Data curation. J. Guerrero: Writing - review \& editing, Investigation, Data curation. M. Herrero: Writing - review \& editing, Data curation. J.C. Merino: Supervision, Project administration, Funding acquisition. J.M. Pastor: Supervision, Project administration, Funding acquisition.

\section{Acknowledgements}

The authors acknowledge the financial support from the "Ministerio de Economía y Competitividad" (Spain) through the project MAT2017-85101-C2 and the Consejería de Educación-Junta de Castilla y León e Instituto para la Competitividad Empresarial de Castilla y León (project VA071G18, CCTT2/18/VA/0002 and grant to María Asensio) and the "Ministerio de Ciencia, Innovación y Universidades” (project PTQ-16-08444 and grant to Julia Guerrero).

\section{Appendix A. Supplementary data}

Supplementary data to this article can be found online at https://doi.org/10.1016/j.polymdegradstab.2020.109258.

\section{References}

[1] S.H. Park, S.H. Kim, Poly (ethylene terephthalate) recycling for high value added textiles, Fash Text 1 (2014) 1-17, https://doi.org/10.1186/s40691-0140001-X.

[2] A.A. Tavares, D.F.A. Silva, P.S. Lima, D.L.A.C.S. Andrade, S.M.L. Silva, E.L. Canedo, Chain extension of virgin and recycled polyethylene terephthalate, Polym. Test. 50 (2016) 26-32, https://doi.org/10.1016/j.polymertesting.2015.11.020.

[3] F. Awaja, D. Pavel, Recycling of PET, Eur. Polym. J. 41 (2005) 1453-1477, https://doi.org/10.1016/j.eurpolymj.2005.02.005.

[4] V. Jankauskaite, Recycled polyethylene terephthalate waste for different application solutions, Environ. Res. Eng. Manag. 72 (2017), https://doi.org/ 10.5755/j01.erem.72.1.15260.

[5] Thermal degradation and catalytic cracking of poly(ethylene terephthalate), Polym. Degrad. Stabil. 63 (1999) 407-412, https://doi.org/10.1016/S01413910(98)00121-9.

[6] X. Zhou, C. Wang, C. Fang, R. Yu, Y. Li, W. Lei, Structure and thermal properties of various alcoholysis products from waste poly(ethylene terephthalate) Waste Manag. 85 (2019) 164-174, https://doi.org/10.1016/ j.wasman.2018.12.032.

[7] S. Chiba, Soo32-3861(96)00282-o, vol. 37, 1996, pp. 4421-4424

[8] L.K. Nait-Ali, X. Colin, A. Bergeret, Kinetic analysis and modelling of PET macromolecular changes during its mechanical recycling by extrusion, Polym. Degrad. Stabil. 96 (2011) 236-246, https://doi.org/10.1016/ j.polymdegradstab.2010.11.004.

[9] S.A. Cruz, C.H. Scuracchio, L.B. Fitaroni, C. Oliveira, The use of melt rheology and solution viscometry for degradation study of post-consumer poly(ethylene terephthalate): the effects of the contaminants, reprocessing and solid state polymerization, Polym. Test. 60 (2017) 236-241, https://doi.org/ 10.1016/j.polymertesting.2017.03.026.

[10] A.F. Ávila, M.V. Duarte, A mechanical analysis on recycled PET/HDPE composites, Polym. Degrad. Stabil. 80 (2003) 373-382, https://doi.org/10.1016/ S0141-3910(03)00025-9.

[11] X. Xu, Y. Ding, Z. Qian, F. Wang, B. Wen, H. Zhou, S. Zhang, M. Yang, Degradation of poly(ethylene terephthalate)/clay nanocomposites during melt extrusion: effect of clay catalysis and chain extension, Polym. Degrad. Stabil. 94 (2009) 113-123, https://doi.org/10.1016/j.polymdegradstab.2008.09.009.

[12] M. Paci, F.P. La Mantia, Competition between degradation and chain extension during processing of reclaimed poly(ethylene terephthalate), Polym. Degrad. Stabil. 61 (1998) 417-420, https://doi.org/10.1016/S0141-3910(97)00227-9.

[13] F. Daver, R. Gupta, E. Kosior, Rheological characterisation of recycled poly(ethylene terephthalate) modified by reactive extrusion, J. Mater. Process. $\begin{array}{llll}\text { Technol. } & 204 & \text { (2008) 397-402, https://doi.org/10.1016 }\end{array}$ j.jmatprotec.2007.11.090.

[14] R.R. Chowreddy, K. Nord-Varhaug, F. Rapp, Recycled poly(ethylene terephthalate)/clay nanocomposites: rheology, thermal and mechanical properties, J. Polym. Environ. 27 (2019) 37-49, https://doi.org/10.1007/s10924-0181320-6.

[15] H. Frenzel, U. Bunzel, R. Häßler, G. Pompe, Influence of different glass fiber sizings on selected mechanical properties of pet/glass composites, J. Adhes. Sci. Technol. 14 (2000) 651-660, https://doi.org/10.1163/156856100742906.

[16] K. Van De Velde, P. Kiekens, Thermoplastic Pultrusion of Natural (B) Bre Reinforced Composites AS NA US SO, 2011, p. 54.

[17] P.J. Novo, J.F. Silva, J.P. Nunes, A.T. Marques, Pultrusion of fibre reinforced thermoplastic pre-impregnated materials, Compos. B Eng. 89 (2016) 328-339, https://doi.org/10.1016/j.compositesb.2015.12.026.

[18] S. Kazemi Najafi, Use of recycled plastics in wood plastic composites - a review, Waste Manag. 33 (2013) 1898-1905, https://doi.org/10.1016/ j.wasman.2013.05.017.

[19] N.(F.) Gilles Orange, Vourles ( Fr ) : Didier Tupinier, Assieu ( Fr ) : Philippe Papin, Bievres ( Fr ); Mickaeel Aubry, Belligné ( Fr ) ; Jean - Michel Lebrun , Nantes ( Fr ) ; Sébastien Comas - Cardona, Method for the Continuous Production of A Composite Material Profile Section from Thermoplastic Polymer Having High Fluidity, 2018.

[20] B.G. Girija, R.R.N. Sailaja, G. Madras, Thermal degradation and mechanical properties of PET blends, Polym. Degrad. Stabil. 90 (2005) 147-153, https:// doi.org/10.1016/j.polymdegradstab.2005.03.003.

[21] A. Elamri, A. Lallam, O. Harzallah, L. Bencheikh, Mechanical characterization of melt spun fibers from recycled and virgin PET blends, J. Mater. Sci. 42 (2007) 8271-8278, https://doi.org/10.1007/s10853-007-1590-1.

[22] M. Ahani, M. Khatibzadeh, M. Mohseni, Preparation and characterization of poly(ethylene terephthalate)/hyperbranched polymer nanocomposites by melt blending, Nanocomposites 2 (2016) 29-36, https://doi.org/10.1080/ 20550324.2016.1187966.

[23] R. Hobzová, J. Peter, P. Sysel, Hyperbranched polymers, Chem. Listy 102 (2008) 906-913, https://doi.org/10.1201/b16588-12.

[24] T.T. Hsieh, C. Tiu, G.P. Simon, Melt rheology of aliphatic hyperbranched polyesters with various molecular weights, Polymer (Guildf) 42 (2001) 1931-1939, https://doi.org/10.1016/S0032-3861(00)00441-9.

[25] N.E. Ikladious, J.N. Asaad, H.S. Emira, S.H. Mansour, Alkyd resins based on hyperbranched polyesters and PET waste for coating applications, Prog. Org. Coating 102 (2017) 217-224, https://doi.org/10.1016/j.porgcoat.2016.10.015.

[26] D. Schmaljohann, P. Pötschke, R. Hässler, B.I. Voit, P.E. Froehling, B. Mostert, J.A. Loontjens, Blends of amphiphilic, hyperbranched polyesters and different 
polyolefins, Macromolecules 32 (1999) 6333-6339, https://doi.org/10.1021/ ma9902504.

[27] A.I. Ares Pernas, M.J. Abad López, M.V. González Rodríguez, M. del M.C. López A.L. Latorre, J.M. López Vilariño, Assessing changes on poly(ethylene terephthalate) properties after recycling: mechanical recycling in laboratory versus postconsumer recycled material, Mater. Chem. Phys. 147 (2014) 884-894, https://doi.org/10.1016/j.matchemphys.2014.06.034.

[28] M.A. Silva Spinacé, M.A. De Paoli, Characterization of poly(ethylene terephthalate) after multiple processing cycles, J. Appl. Polym. Sci. 80 (2001) 20-25, https://doi.org/10.1002/1097-4628(20010404)80:1<20::AIDAPP1069>3.0.CO;2-S.

[29] R. Assadi, X. Colin, J. Verdu, Irreversible structural changes during PET recycling by extrusion, Polymer (Guildf). 45 (2004) 4403-4412, https://doi.org/ 10.1016/j.polymer.2004.04.029.

[30] K. Van Kets, L. Delva, K. Ragaert, Structural stabilizing effect of SEBSgMAH on a PP-PET blend for multiple mechanical recycling, Polym. Degrad. Stabil. 166 (2019) 60-72, https://doi.org/10.1016/j.polymdegradstab.2019.05.012.

[31] A. Ramírez-Hernández, M. Valera-Zaragoza, A. Aparicio-Saguilán, J.C. CondeAcevedo, Thermal behavior of banana starch films with degraded polyethylene terephthalate, Rev Mex Ing Quim 14 (2015) 513-521.
[32] A.P. Dos Santos Pereira, M.H.P. Da Silva, É.P. Lima, A. Dos Santos Paula, F.J. Tommasini, Processing and characterization of PET composites reinforced with geopolymer concrete waste, Mater. Res. 20 (2017) 411-420, https:// doi.org/10.1590/1980-5373-MR-2017-0734.

[33] M. Härth, J. Kaschta, D.W. Schubert, Rheological study of the reaction kinetics in a poly(ethylene terephthalate) melt, Polym. Degrad. Stabil. 120 (2015) 70-75, https://doi.org/10.1016/j.polymdegradstab.2015.06.001.

[34] J.M. Besnoin, K.Y. Choi, Identification and characterization of reaction byproducts in the polymerization of polyethylene terephthalate, J. Macromol. Sci. Part C 29 (1989) 55-81, https://doi.org/10.1080/07366578908055164.

[35] A. Oromiehie, A. Mamizadeh, Recycling PET beverage bottles and improving properties, Polym. Int. 53 (2004) 728-732, https://doi.org/10.1002/pi.1389.

[36] J.D. Badía, F. Vilaplana, S. Karlsson, A. Ribes-Greus, Thermal analysis as a quality tool for assessing the influence of thermo-mechanical degradation on recycled poly(ethylene terephthalate), Polym. Test. 28 (2009) 169-175, https://doi.org/10.1016/j.polymertesting.2008.11.010.

[37] F. Samperi, C. Puglisi, R. Alicata, G. Montaudo, Thermal degradation of poly(ethylene terephthalate) at the processing temperature, Polym. Degrad. Stabil. 83 (2004) 3, https://doi.org/10.1016/S0141-3910(03)00166-6. 